\title{
Factors contributing to low institutional deliveries in the Marondera district of Zimbabwe
}

\author{
E Mugweni, MA Cur student \\ MA Cur graduate, Department of Health Studies, University of South Africa \\ VJ Ehlers, D Litt et Phil \\ Professor, Department of Health Studies, University of South Africa \\ JH Roos, D Litt et Phil \\ Senior Lecturer, Department of Health Studies, University of South Africa
}

Keywords:

Ante-natal care, home delivery, institutional delivery, midwifery in Zimbabwe, women's health in Zimbabwe.

\section{Correspondence address:}

\section{Prof VJ Ehlers}

Department of Health Studies

PO Box 392

Unisa

0003

Tel : (012) 429-67321(w)

Fax: (012) 429-6688(w)

Cell: 0845873303

E-mail: ehlervj@unisa.ac.za

\section{Abstract: Curationis 31(2): 5-13}

The purpose of the study was to identify factors contributing to low institutional deliveries in the Marondera District, Zimbabwe, among women who attended antenatal clinics, in order to enhance the number of institutional deliveries. A quantitative descriptive survey, gathering data by conducting structured interviews with 80 women, was used in this study. All 80 women attended ante-natal clinics but 40 delivered at home and 40 delivered at an institution.

The Health Belief Model (HBM) was used to contextualise the data. The research results indicated that factors that contributed to the low number of institutional deliveries included that women's minimal expectations of cleanliness and noninterference during labour and delivery could be met during home deliveries; institutional deliveries' costs included traveling expenses, losing family support and the inability to meet cultural expectations; women's lack of knowledge about danger signs of pregnancy; and women's negative perceptions of nurses working at the institution(s). The recommendations include reduced costs of institutional deliveries; allowing family members (especially the mother-in-law) to be present during institutional deliveries and to perform cultural rituals whenever possible. The nurses' attitudes and competence levels should be addressed through in-service education sessions and sustained follow-up evaluations, including evaluations by pregnant women.

\section{Introduction and background information}

The health of women is an important contributing factor to the overall health of any nation. The World Health Organization (WHO) 'Maternal-Baby Package' emphasises that the key to safe motherhood is appropriately trained midwives (WHO, 1999:18). Safe motherhood is defined as the provision of high quality maternal health services during pregnancy, delivery and in the postpartum period to ensure the health of the mother and infant (WHO, 2000:23). The four pillars of safe motherhood are cited as antenatal care (ANC), clean and safe assisted delivery, essential obstetric care and family planning (WHO,1999:17).

Zimbabwe's Ministry of Health and Child Welfare (MOHCW, 2001:8) aims to reduce morbidity and mortality related to pregnancy and childbirth through providing 
enhanced access to ANC and safe assisted deliveries in hygienic environments.

\section{Problem statement}

The primary health care (PHC) clinics in the Marondera District provide ANC services to pregnant women. However, safe assisted deliveries and essential obstetric care cannot be provided for women opting for home deliveries, because trained midwives and equipment are not available in women's homes. Proper care during labour and delivery constitutes an important prerequisites for reducing morbidity and mortality risks for both mothers and babies (WHO, 1999:27). This situation is particularly serious in Zimbabwe where $91 \%$ of the women attended ANC clinics (in the Masvingo Province of Zimbabwe), but the institutional deliveries averaged $51 \%$ (Mbizvo, Fawcus, Lindmark, \& Nystrom, 1993:371).

The question that requires answers is why women who attend ANC clinics in the Marondera District continue to deliver their babies at home, explaining the disparity between the number of ANC bookings and institutional deliveries in this district.

\section{Purpose of the study}

The main purpose of this study was to identify factors influencing women's preferences for home deliveries rather than institutional deliveries in the Marondera District of Zimbabwe, to account for the low number of institutional deliveries in this area. Based on the research results, recommendations will address women's needs/preferences so that the number of home deliveries could decrease and the number of institutional deliveries among ANC booked women could increase.

\section{Research questions}

The research questions and objectives are formulated according to the major concepts of the Health Belief Model (HBM), described by Onega (2000:271) as individual perceptions, modifying factors and variables affecting the likelihood of initiating actions.

The major research question was: what factors influence women who attend ANC clinics in the Marondera District to deliver their babies at home? These factors were then categorised according to individual perceptions, modifying factors and variables affecting the likelihood of women's actions to deliver their babies either at home or at a health care institution. The data obtained in response to these questions will be used to answer the second research question, namely: What recommendations can be made to enhance women's utilisation of institutional delivery services in the Marondera District?

\section{Objectives}

The objectives guiding this study were to identify

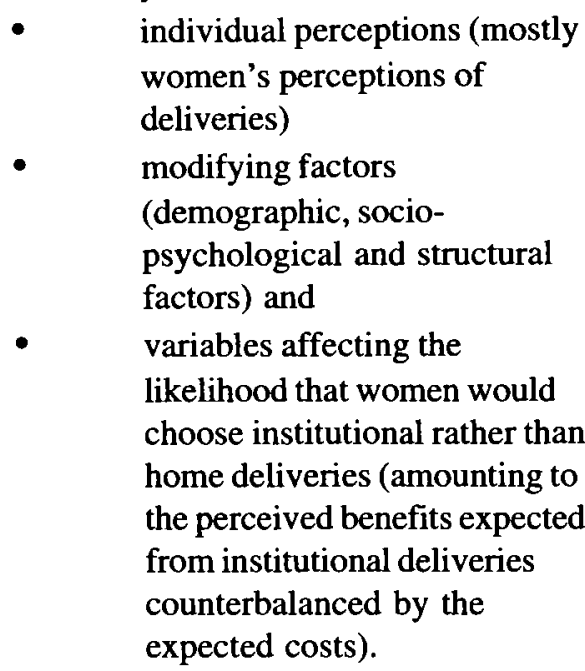

The final objective of this study was to use the data obtained to make recommendations to increase the number of institutional deliveries, and reduce the number of home deliveries, among women who attend ANC clinics in the Marondera District.

\section{Assumptions}

In terms of the HBM's major components (Onega, 2000:271), the assumptions underlying this study were that:

- $\quad$ individual perceptions of women influenced their decisions to deliver their babies at home rather than at a health care institution

- $\quad$ a number of modifying factors might have influenced women's decisions as to their preferred place of delivery

- women's perceived benefits of institutional deliveries should outweigh the perceived costs before they could take actions to deliver their babies in health care institutions rather than to opt for home deliveries.

Research methodresearch

\section{design}

The study was a descriptive, quantitative cross sectional survey using a structured interview schedule to collect data. With this descriptive study the researchers attempted to gain new information about the factors influencing booked ANC women to opt for home rather than institutional deliveries in the Marondera District (Burns \& Grove, 2001:268). The descriptive design involved describing and classifying factors influencing low numbers of institutional deliveries in this district, in quantitative (numerical) forms using descriptive statistics. It was a cross-sectional survey because all the pregnant women attending ANC clinics and who delivered their babies, either at home or at an institution, during September 2003, comprised the population for this study.

\section{Research setting}

The study was carried out during September 2003 at one hospital in the Marondera District of Zimbabwe. The PHC centre serves the needs of 33317 people (Mugweni, 2004:52). The rural health hospital had five registered general nurses and three midwives.

\section{Population and sample}

The research population comprised all women who attended ANC and who delivered their babies either at home or at the hospital during September 2003. The sample comprised 80 women who had utilised ANC services during 2002/3 and who delivered their babies during September 2003; 40 women who delivered at home and 40 who delivered at the hospital. This amounted to a retrospective study because it started with women (who attended ANC clinics) having delivered their babies either at home or at an institution during September 2003 and then attempted to identify factors that influenced these women's decisions for their selected delivery venues.

\section{Sampling procedure}

A list (census) of all post-natal women, who had used ANC services during 2002/ 3 , was available indicating which women delivered their babies at home and which women did so at a health care institution. Separate lists were compiled for these two groups of women and a number was assigned to each woman on each list. A table of random numbers (Burns \& Grove, 2001:760) was used to select 40 women 
from each list randomly. The 80 women comprising the sample came from 33 villages in the Marondera District.

\section{Ethical considerations}

Permission to conduct this study was requested from and granted by the Medical Research Council of Zimbabwe, the Provincial Medical Director of Mashonaland East Province, the District Council, the District Health Executive and the Councillors of Wards 10-15 in the Marondera District. The research proposal was also accepted by the Ethics and Research Committee of the Department of Health Studies, University of South Africa.

Verbal consent was granted by each participant after the purpose of the study had been explained. Subjects were informed that they had the right to refuse to participate, to withdraw from participation at any stage and to refuse to answer specific questions without suffering any ill effects whatsoever. No remuneration was paid for participation and no expenses were incurred by participants, as they were interviewed in the privacy of their own homes. No names were written on any interview schedules, but each name was crossed out from the samples' lists after each interview. The subjects were informed that the information would be used to compile a research report but that no names would be disclosed. The interviewer's contact details were supplied should a woman wish to ask questions at any stage.

\section{Research instrument}

Face to face structured individual interviews were conducted to collect data. The structured interview schedule's items, based on information obtained from a literature review, were both closedand open-ended. The interview schedule was not structured according to the major tenets of the HBM to avoid creating specific mindsets in the interviewees and/ or research assistants. The instrument comprised the following sections:

- 1 - requested biographic and
ANC information (7 items)
2 - focused on socio-
demographic data (7 items)
3 - enquired about women's
perceptions of Marondera
District's nurses rendering
maternity services (12 items)

4 - investigated the

affordability and accessibility of maternity services ( 3 items)

5 -identified cultural practices that could influence women's choices of delivery venues ( 3 items)

-

6-elicited information about respondents' knowledge about safe assisted deliveries (6 items).

\section{Validity and reliability of the structured interview schedule}

Validity refers to the extent to which the research instrument actually measures what it is supposed to measure, implying that it "reflects the abstract construct being examined" (Burns \& Grove, 2001:814). In this study, face validity was based on the judgments of experts in the field of midwifery services (Polit \& Hungler, 1999:255). The structured interview schedule's items were derived from a literature review, and it was submitted to the midwives and registered nurses working at PHC clinics in the Marondera District. The statistician and two nurse researchers scrutinised the instrument's items. All the persons consulted, agreed that the interview schedule's items were relevant to factors that could influence women's choices to deliver their babies at home or at health care institutions. Two nurse researchers, familiar with the Health Belief Model, agreed that the contents of the participants' answers could be categorised according to the major tenets of this theory.

Reliability refers to the "... degree of consistency or dependability with which an instrument measures the attribute it is designed to measure" (Polit \& Hungler, 1999:653). A pre-test was done during which six women, excluded from participation in the actual study, was done to determine the clarity of the items and the consistency of the responses. No discrepancies between responses obtained during the pre-test and the actual data collection phase occurred. No discrepancies were observed in the interview schedules completed by the two interviewers.

Inter-rater reliability refers to "the degree of consistency between two raters who are independently assigning ratings to a variable or attribute being investigated" (Polit \& Hungler 1999:801). Two research assistants independently interviewed a total of 80 women (each interviewer completed 40 structured interview schedules) and no discrepancies were detected in their recorded responses. The first author and the statistician who coded and entered the data on the Epi Info program could not distinguish between structured interview schedules completed by the two interviewers. No statistics were computed to verify this observation.

\section{Data collection procedures}

The instrument was translated into Shona by a Shona-speaking researcher and the translations were checked and approved by a Shona-speaking teacher who taught English at Marondera's secondary school. The interviews were conducted by two research assistants, trained by the first author, who spoke Shona fluently. The instrument was pretested by conducing interviews with six women who delivered their babies in another district (three delivered at home and three delivered at an institution) which did not participate in the actual study. No changes were necessary as the women understood the questions. The interview schedules completed by the research assistants were evaluated by a Shona speaking researcher (the first author of this article), and further training was provided to the research assistants about the dire necessity to complete the structured interview schedule as fully as possible.

The 80 interviews (lasting approximately 30 minutes each) were conducted by the two Shona speaking research assistants over a period of 21 days, because women had to be visited in 33 villages with poor access roads. Every completed interview schedule was reviewed by the researcher and discussed with the research assistant on the day of its completion.

\section{Data analysis}

Data analysis was done using the Epi Info Version 2002 Package. Descriptive statistical methods were used to analyse the data. Single table analyses were used to determine the potential impact of the factors influencing women to deliver their babies at home rather than at health care institutions.

The Shona responses to the open-ended questions were recorded verbatim, translated into English by the first author, and checked for consistency by a Shonaspeaking English teacher from the local 
high school. These responses were grouped and analysed quantitatively.

\section{Research results : data analyis and interpretation}

The results will be presented according to the sections of the structured interview schedule and thereafter discussed in terms of the major tenets of the HBM. The biographic and ANC information of the 80 interviewees will be presented initially so that the rest of the data can be contextualised against this information.

\section{Biographic and ANC information}

Out of a total of 80 respondents $40(50 \%)$ delivered their babies at a health facility. Respondents came from 33 villages.

\section{Age}

The modal age of respondents was 23 , the youngest respondent was 16 and the oldest respondent was 38 years old.

\section{ANC attendances}

Table 2 indicates that the maximum number of ANC visits was 6 and the most frequent number (mode) of visits was 3 , contrary to the recommended MOHCW (2001:27) ideal number of 6 visits.

\section{Socio-demographic factors}

In order to interpret women's preferences for home versus institutional deliveries, questions were asked about their marital status, educational levels and occupations.

\section{Marital status}

The majority of the respondents $(85.0 \%$; $\mathrm{n}=68$ ) were married, with no marked difference between those who chose home versus institutional deliveries.

\section{Parity}

Table 3 shows that only $16(61.5 \% ; n=$ 26) of the respondents with parity one delivered their babies at hospital, while all respondents with parity five or more delivered at home.

Table 2 Number of ANC visits: home versus institutional deliveries $(n=68)$

\begin{tabular}{|c|c|c|}
\hline Number of ANC visits & Home deliveries & Institutional deliveries \\
\hline 1 & 3 & 1 \\
\hline 2 & 9 & 2 \\
\hline 3 & 7 & 8 \\
\hline 4 & 6 & 4 \\
\hline 5 & 8 & 6 \\
\hline 6 & 4 & 10 \\
\hline
\end{tabular}

Table 3 Parity of respondents $(n=80)$

\begin{tabular}{|l|llllll|}
\hline & Para 1 & Para 2 & Para 3 & Para 4 & Para 5 \\
\hline Entire sample & 26 & 26 & 14 & 6 & 8 \\
\hline Home deliveries & 10 & 13 & 6 & 3 & 8 \\
\hline Institutional deliveries & 16 & 13 & 8 & 3 & 0 \\
\hline
\end{tabular}

\section{Education levels}

Table 4 reveals that the level of education had no statistically significant influence on the chosen place of delivery. All the women received some schooling and the majority acquired secondary education, as from the eighth year of schooling in Zimbabwe.

\section{Occupational status}

Poverty could limit the utilisation of health services (WHO 1999:14).

No respondent was employed in the formal economic sector, reflecting the scarcity of jobs in this rural area of Zimbabwe, despite these women's educational accomplishments.

\section{Women's perceptions of maternity services in the}

Table $1:$ Age of respondents: home versus institutional deliveries $(n=80)$

\begin{tabular}{|l|l|l|}
\hline Age group & No of home deliveries & No of institutional deliveries \\
\hline $10-19$ & 7 & 5 \\
\hline $20-29$ & 25 & 30 \\
\hline $30-39$ & 8 & 5 \\
\hline
\end{tabular}

\section{Marondera District}

Concerning their perceptions/ experiences with maternity services in the Marondera District respondents from both the home and institutional delivery groups, were dissatisfied with the:

- Welcoming attitude of nursing staff $(85.0 \%)$.

- $\quad$ Patience of nursing staff (73.8\%).

- Friendliness of nursing staff (72.5\%).

Talking to you in an understandable way $(72.5 \%)$.

Listening to you while you are talking $(61.2 \%)$.

- $\quad$ Offering of a seat $(57,5 \%)$.

- Performance of physical examination (55\%).

- $\quad$ Taking of nursing history (53.8\%).

- General information and explanation of procedures and examinations $(52.5 \%)$

Specific information on danger signs and complications during pregnancy (48.85\%).

Specific information about pregnancy $(47.5 \%)$ 
Table 4 Level of education: institutional versus home deliveries $(n=80)$

\begin{tabular}{|l|c|c|c|l|}
\hline Place of delivery & $\mathbf{1 - 7}$ years' schooling & $\mathbf{8 - 1 1}$ years' schooling & $\mathbf{1 2 - 1 3}$ years' schooling & Total \\
\hline Home & 6 & 32 & 2 & 40 \\
\hline Institutional & 7 & 31 & 2 & 40 \\
\hline Total & 13 & 63 & 4 & 80 \\
\hline
\end{tabular}

Table 5 Occupational status of respondents $(n=80)$

\begin{tabular}{|l|l|l|}
\hline Occupation & Frequency & Percentage \\
\hline Self employed & 6 & 7.5 \\
\hline Farm worker & 2 & 2.5 \\
\hline Peasant farmer & 49 & 61.2 \\
\hline Unemployed & 6 & 7.5 \\
\hline Others & 17 & 21.7 \\
\hline Total & 80 & 100 \\
\hline
\end{tabular}

\section{Affordability/accessibility of maternity services in the Marondera District}

The majority of respondents who delivered at home $(60 \% ; n=24)$ would have paid more than $\mathrm{Z} \$ 500.00$ for transport to get to the health facility while $37.5 \%(n=15)$ of those who delivered at the institutions paid this amount. This suggests that many respondents who delivered at home might have lived further away from the health facility than their counterparts. However, home delivery services appeared to be more expensive than institutional ones. As many as $92.5 \%(n=37)$ of the women who delivered at home paid $\mathrm{Z} \$ 500$ or more for these services compared to $15 \%(n=6)$ of their counterparts who delivered at institutions.

\section{Cultural practices}

Table 6 shows that the majority of respondents who delivered at home agreed with cultural practices.

The respondents who delivered at home gave the following reasons in response to an openended question:

- The in-laws demanded that I deliver at home

- I had nobody to leave at home

- I like delivering at home for continued care

- The health facility is too far

- Health staff members are rude.

\section{Knowledge about safe assisted deliveries}

Both respondents who delivered at home and those who delivered at the health institution expressed that the following aspects of safe assisted deliveries were important to them:

- No interference during labour (75\%)

- Clean cutting of the cord

\section{(72.5\%)}

- $\quad$ No interference during delivery of the baby and placenta (72.5\%)

- Clean surface for delivery (64.8\%)

- Clean hands and body (63.8\%)

- A clean environment (61.2\%)

- Clean hands (61.2\%)

\section{Knowledge about danger signs of pregnancy}

The only conditions for which at least $60 \%(n=24$ in each group) pregnant women would seek medical attention were for vaginal bleeding and labour pains that lasted for more than 12 hours.

Table 7 reveals that a traditional midwife assisted most respondents, followed by the women's mothers while only one was assisted by her mother-in-law. In response to an open-ended question, 19 (23.8\%) respondents experienced the following problems

- Abdominal pains and vaginal bleeding

- Baby aspirated

- Backache

- $\quad$ Child's hand came first

- Mother could not pass urine

- Deep tear on the perineum

- Dizziness

\section{Table 6 Cultural practice versus place of delivery}

\begin{tabular}{|c|c|c|c|c|c|c|c|c|}
\hline \multirow{3}{*}{ Cultural aspect } & \multicolumn{3}{|c|}{ Home deliveries $(n=40)$} & \multicolumn{5}{|c|}{ Institutional deliveries $(n=40)$} \\
\hline & \multicolumn{2}{|c|}{ Yes } & \multirow{2}{*}{$\begin{array}{l}\text { No } \\
\mathbf{n} \\
\end{array}$} & \multicolumn{2}{|c|}{ Yes } & \multicolumn{3}{|l|}{ No } \\
\hline & n & $\%$ & & $\%$ & n & $\%$ & n & $\%$ \\
\hline * Masungiro & 30 & 75 & 10 & 25 & 13 & 32.5 & 27 & 67.5 \\
\hline In-laws' demands (to prove it is the son's child) & 24 & 60 & 16 & 40 & 14 & 35 & 26 & 65 \\
\hline In-laws' demands (to fulfill cultural rituals) & 25 & 62 & 15 & 37 & 4 & 10 & 36 & 90 \\
\hline
\end{tabular}

* Musingiro is a Shona term denoting the cultural practice that a woman should deliver her first born child at her parents' home so that the family can provide support during delivery and in caring for the newborn baby. 
Table 7 Persons who assisted respondents who delivered at home $(n=40)$

\begin{tabular}{|l|l|l|}
\hline Person who assisted & frequency & percentage \\
\hline Traditional midwife & 27 & 67.5 \\
\hline Mother & 10 & 25.0 \\
\hline Mother-in law & 1 & 2.5 \\
\hline Self & 2 & 5.0 \\
\hline Total & 40 & 100 \\
\hline
\end{tabular}

- $\quad$ Excessive bleeding

- Vaginal bleeding for three months

- $\quad$ Retained placenta

- Swollen breasts

\section{Research results discussed within the major tenets of the health belief model (hbm)}

The research results will be presented according to the major tenets of the HBM, namely individual perceptions, modifying factors and variables affecting the likelihood of initiating actions.

\section{Individual perceptions}

Onega (2000:271) defines individual perceptions as a person's beliefs about his/her own susceptibility to disease, or ill effects, and the seriousness with which he/she views this perceived threat. Although all $80(100 \%)$ women who participated in this study attended ANC clinics, and $50.0 \%(n=40)$ of them delivered their babies at a health care institution, $75.0 \%(\mathrm{n}=30)$ wanted no interference during the labour process and $72.5 \%(n=58)$ also wanted no interference during the delivery of the baby and placenta. Based on these individual perceptions, home deliveries appeared to be more acceptable than institutional deliveries.

Those eight women who delivered their fifth or subsequent baby did so at home while 10 (out of 26) women delivered their first babies at home. Women with parity one as well as those with parity five or greater are at increased risk of maternal and perinatal mortality and morbidity and should deliver their babies at sites with referral and transfer facilities to a higher level health care institution better equipped than PHC clinics to deal with potential obstetric and neonatal complications (WHO 1999:5). These women exposed themselves and their babies to potential risks by opting for home deliveries. Both these groups of women fall into obstetric high risk groups and should have delivered at a health care institution, but preferred to do so at home, probably based on their individual perceptions of expecting no harm to themselves or to their babies, and preferring no interference during the labour and delivery processes. This perception might also have accounted for the finding that $22.5 \%(n=18)$ of the women commenced their ANC visits during the first, $41.3 \%(n=33)$ during the second and $35.0 \%(n=28)$ during the third trimester. Only $17.5 \%(n=14)$ of the women attended the ANC clinic at least six times during their pregnancies, indicating that these women might not have realised the importance of ANC visits and institutional deliveries. Among the respondents who delivered at home, $9(22.5 \%)$ had only 2 ANC visits. WHO (1999:6) recommends that women should begin ANC care during the first trimester, before 16 weeks of pregnancy. The respondents did not necessarily benefit from the ANC services provided in the area because out of the 80 women, only 22.5\% $(n=18)$ commenced their ANC visits during their first trimester, while $41.3 \% \quad(n=33)$ did so during the second and $35.0 \%(n=28)$ during the third trimester. In spite of the fact that all 80 $(100 \%)$ of the participants had attended ANC, they lacked knowledge about the danger signs of pregnancy, as $70.0 \%$ ( $n=56$ ) did not realise the importance of seeking medical help for signs of potential eclampsia/pre-eclampsia.

These participating women's individual perceptions about non-interference and cleanliness during the labour and delivery processes, their lack of knowledge about some danger signs of pregnancy, as well as their negative perceptions of the nurses might have influenced their decisions to deliver their babies at home rather than at an institution. Both groups of women indicated that they were dissatisfied with the nurses' welcoming attitude $(85.0 \%)$; patience $(73.8 \%)$; friendliness $(72.5 \%)$ and way of talking to the patients $(72.5 \%)$.

\section{Modifying factors}

According to Onega (2000:271) modifying factors include demographic, socio-psychological and structural factors influencing individual persons' health-related decisions and actions.

\section{Demographic factors}

There were no significant differences between the women who delivered their babies at home compared to those who delivered at a health care institution concerning their ages, marital-, occupational- or educational status. No woman was employed in the formal sector, $61.0 \%(n=49)$ were peasant farmers with limited incomes despite the fact that $83.75 \%(n=67)$ had completed $8-13$ years' schooling. This high level of schooling should enable these women to understand the importance of institutional deliveries, especially for those aged up to 19 as well as those aged 35 or older, and for all primigravidas and multigravidas. Table 1 indicates that 8 women in the 30-39 year age group reported home deliveries. Bennett and Brown (2001:214) remarked that older women are a high risk age group with increased risks of perinatal mortality and post partum haemorrhage (PPH). These women should give birth at a health care facility that can arrange transfer to an institution equipped to deal with potential obstetric complications (WHO, 1999:5).

With their reported high levels of education, Zimbabwe's pregnant women should be able to make informed choices concerning institutional versus home deliveries, if the relevant information is provided at the ANC clinics. Table 2 indicates that most pregnant women visited the ANC clinics only three times during their pregnancies, limiting the opportunities for receiving effective health education.

As many as $61.2 \%(n=49)$ of respondents were peasant farmers (see table 5). Yields from peasant farming depend on rainfall necessitating reliance on food aid from 
the government of Zimbabwe during droughts. Women facing potential food shortages might be unlikely to use institutional delivery services if these involve travel and other costs avoidable by opting for home deliveries.

\section{Socio-psychological variables}

In this study these variables implied cultural expectations, as reflected in table 6 , indicating that more women who delivered their babies at home adhered to cultural practices than those who delivered at an institution. The acceptability of the maternity services were influenced negatively by the women's perceptions that they might be unable to meet cultural expectations if their babies are delivered at institutions, family support would not be available and their negative perceptions of the nurses working at these services (as discussed under "individual perceptions" in this article).

\section{Structural variables affecting the likelihood of action}

The major structural variables that affected the likelihood of the participating women to deliver their babies at an institution were their knowledge as well as the affordability, accessibility and acceptability of maternity services in the Marondera District.

In both groups only $30.0 \%$ ( $n=12$ in each group) would seek medical help for dizziness/blurred vision/generalised oedema, implying that as many as $\mathbf{7 0 . 0 \%}$ could delay seeking medical help for potential signs of eclampsia. The severity of this situation is emphasised by reports that the majority of Zimbabwe's obstetric deaths are due to abortion-related complications and to severe pre-eclampsia/eclampsia (Mudokwenyu-Rawdon, 2001:16). Women's lack of knowledge could have been a structural variable influencing their decisions not to deliver their babies at health care institutions. All the problems reportedly experienced by the participants during and after home deliveres (excluding backache and swollen breasts) might involve obstetric emergencies with enhanced risks of mortality and morbidity for both the mother and the baby. Women with these reported obstetric complications (severe abdominal pains, aspiration of baby, child's hand came first, mother could not pass urine, deep tear in the perineum, dizziness, excessive bleeding, vaginal bleeding for three months, retained placenta) should have delivered their babies at a health care institution, and/ or obtained obstetric help during and after delivery.

Those women who delivered their babies at an institution probably lived closer to the institution because their transport costs were less than the estimated costs for women who delivered at home. However, the cost for institutional deliveries were cheaper than home deliveries, but institutional deliveries involved additional costs of traveling, finding child minders and getting someone else to look after the woman's home and fields, for those who were peasant farmers. As all 80 participating women attended ANC clinics, institutional deliveries should have been accessible to all of them.

\section{Variables affecting the likelihood of initiating actions}

In terms of the HBM, minimal benefits expected from institutional deliveries MINUS the expected costs EQUALS the likelihood that women would deliver their babies at an institution (rather than at home).

\section{Minimal expected benefits}

Both groups' minimal expectations during labour and delivery included noninterference and cleanliness - which could also be met during home deliveries. The minimal expectations during an institutional delivery include the effective monitoring of the labour process as well effective monitoring of the mother and the baby after delivery, and timely referral to higher level services should any complication be suspected. The perceived effectiveness of such monitoring could be compromised by women's negative perceptions of nurses working at the institution.

\section{Expected costs}

The expected costs of an institutional delivery include traveling expenses, payment for the delivery, forfeiting family support during the delivery process, non-adherence to cultural expectations, and getting someone to take care of the home and children during the woman's absence. Although home deliveries were reportedly more expensive than institutional deliveries, the additional costs of institutional deliveries might have made the latter option more expensive for these women with limited incomes.
The likelihood of initiating actions for an institutional delivery (rather than a home delivery)

These women's minimal expectations for assistance during and after a delivery could be met at home as well as at an institution. The total costs incurred by an institutional delivery outweighed those of a home delivery. Therefore the conclusion, based on the HBM, could be reached that: women's expectations during delivery - minus greater costs of an institutional delivery $=$ greater likelihood of a home delivery.

\section{Limitations}

The study was limited to one rural health center because it was the only health center offering maternity services at the time of data collection (September 2003). The study was also limited to women who had utilised ANC services and delivered at home or at the health institution in this area. Consequently the research results cannot be generalised to other areas in Zimbabwe, nor to Zimbabwean women who did not attend ANC clinics. A random sample of 80 women had been selected. However, no inferential statistics were done to extrapolate the results obtained from the 80 participating women to the population of pregnant women in the Marondera district of Zimbabwe because the sample size was small.

Only structured interviews were conducted. More in-depth information might have been obtained by conducting individual and/or focus group interviews. No data were gathered from the nurses to compare and contrast the data obtained from the women.

\section{Conclusions}

Individual perceptions that influenced women's decisions to deliver their babies at home included that they preferred cleanliness as well as no interference during labour and during the delivery of the baby and placenta. The interviewees did not realise the potential dangers of home deliveries, especially for primigravidas and multigravidas, despite their high levels of education. ANC clinic attendances commenced late and were too few.

Cultural expectations, greater expenses incurred by institutional deliveries as well as the perceived negative attitudes of nurses, influenced women's decisions 
to deliver their babies at home. The low minimal expectations of institutional deliveries (cleanliness and noninterference), the perceived high costs of institutional deliveries compared to home deliveries, and nurses' perceived unfriendliness influenced these women to opt for home deliveries. The number of institutional deliveries in the Marondera District are unlikely to increase until these perceived shortcomings have been addressed.

\section{Recommendations}

In order to enable more women in the Marondera District to deliver their babies at a health care institution, and enhance the safety and wellbeing of pregnant women and newborn babies, the following recommendations should be heeded:

- $\quad$ ANC clinics should emphasise the advantages of institutional deliveries and assure pregnant women that no unnecessary interference will occur during labour nor during the delivery of the baby and placenta.

Midwives' preferences for managing labour and delivery processes in the Marondera

District of Zimbabwe should be investigated, and adjusted in accordance with pregnant women's preferences for cleanliness and no interference during these processes. Should active interventions become necessary, midwives should inform the woman and her significant others and obtain permission prior to implementing any intervention, if possible. Emergency interventions should be explained to the woman and her significant others as soon as possible. Pregnant women should be informed about their rights in this regard during their ANC visits.

- $\quad$ Health education at ANC clinics should emphasise that all primigravidas and all multigravidas (with the fifth or subsequent pregnancy) should deliver their babies at health care institutions; and all women who experienced previous obstetric problems.

- Health education at ANC clinics should emphasise the danger signs of eclampsia/preeclampsia and the dire necessity to seek help timeously.

- All pregnant women aged 19 or younger, as well as those who are 35 or older, should deliver at health care institutions.

- At least six ANC visits should be encouraged and these should commence during the first trimester of pregnancy (prior to 16 weeks' gestation).

- Health care institutions should provide facilities for cultural practices during and after delivery such as enabling the mother-in-law to be present during the birth, to fulfill cultural rituals and to help care for the newborn baby.

- $\quad$ The possibility should be investigated to build self-care shelters for pregnant women near the hospital so that they will not need to find expensive transport once the labour process started.

- The charges levied for ANC visits and institutional deliveries should be affordable for rural women.

Future studies should investigate the:

- factors that influence women with high parity to deliver at home

- barriers to effective communication between nurses and clients

- $\quad$ quality of maternity services rendered in the Marondera District.

"African women of reproductive age have the highest death risk from maternal causes of any women in the world. The lifetime chance of maternal death is 1:21 in Africa as compared to 1:54 in Asia, which ranks second... The (African) continent accounts for $30 \%$ of all maternal deaths in the world as against 18\% of births" (Paul 1993:745). This situation remains unlikely to change as long as large numbers of African women opt for home deliveries. This study identified some factors which could be addressed to enable more women to deliver their babies at a health care institution in the Marondera District of Zimbabwe which could help to reduce maternal and infant mortality and morbidity figures in this area.

\section{References}

BENNETT, VR \& BROWN, LK 2001.

Myles' textbook for midwives. $13^{\text {th }}$

Edition Edinburgh: Churchill

Livingstone.

BURNS, N \& GROVE, SK 2001. The practice of nursing research: conduct, critique and utilization. Philadelphia: WB Saunders.

MBIZVO, MT; FAWCUS, S; LINDMARK, G \& NYSTROM, L 1993. Operational factors of maternal mortality in Zimbabwe. Health Policv and Planning. 8(4):369-378.

MINISTRY OF HEALTIIAND CHILD WELFARE 2001. Reproductive health services: delivery guidelines. Harare: Government Printer.

\section{MOHCW see MINISTRY OF HEALTH AND CHILD WELFARE (of Zimbabwe)}

MUDOKWENYU-RAWDON, C 2001. Factors influencing pregnancy outcomes in high-risk patients. Unpublished D Litt et Phil thesis. Pretoria: University of South Africa.

MUGWENI, E 2004. Factors contributing to the disparity between antenatal bookings and institutional deliveries in Marondera District. Unpublished MA Cur dissertation. Pretoria: University of South Africa.

ONEGA, LL 2000. Educational theories, models and principles applied to community and public health nursing in Stanhope, M \& Lancaster, J 2000. Community and public health nursing. $5^{\text {th }}$ edition. St Louis: CV Mosby.

PAUL, KB 1993. Maternal mortality in Africa: 1980-1987. Social Science \& Medicine. 37(6):745-752.

POLIT, DF \& HUNGLER , BP 1999.

Nursing research principles and methods. $6^{\text {th }}$ edition. Philadelphia: JB Lippincott.

STANHOPE, M \& LANCASTER, J 1992. Community health nursing process and practice for promoting health. St Louis: CV Mosby. WHO - see WORLD HEALTH
ORGANIZATION. 
WORLD HEALTH ORGANIZATION

2000. Safe motherhood: a newsletter of worldwide activity. Issue 28 . Geneva.

WORLD HEALTH ORGANIZATION

1999. Reduction of maternal mortality: a

joint WHO/UNFPA/UNICEF/

World Bank Statement. Geneva. 